\title{
OXYGEN CONSUMPTION OF HUMAN SPERMATOZOA IN SEMINAL PLASMA AND A RINGER SOLUTION
}

\author{
R. ELIASSON \\ Reproductive Physiology Unit, \\ Department of Physiology, Faculty of Medicine, \\ Karolinska Institutet, Stockholm, Sweden \\ (Received 14th December 1970, revised 29th March 1971)

\begin{abstract}
Summary. The oxygen consumption of human spermatozoa has been determined polarographically with Clark electrodes both in whole semen and in a buffered Ringer solution. Washing of the spermatozoa caused an average decrease of $13 \%$ in the number of live cells. The oxygen consumption of the spermatozoa was two to three times higher in the Ringer solution than in the whole semen $(P<0 \cdot 001)$.

If the washed spermatozoa were returned to their own seminal plasma, the oxygen consumption also returned to the original level. These results indicated that human seminal plasma normally contains a factor that depresses sperm respiration.
\end{abstract}

\section{INTRODUCTION}

In a previous study, it was reported that the oxygen consumption of human spermatozoa in their own seminal plasma was significantly lower in specimens obtained from patients with prostato-vesiculitis than in those from healthy men (Eliasson, 1970). In some samples, the oxygen uptake was too low to be measured. To study the mechanism behind this depressed respiration, further experiments were carried out with washed spermatozoa. When corrections were made for the increase in dead spermatozoa following the washing procedure, the oxygen uptake of the spermatozoa was two to three times higher in a buffered Ringer solution than in the native specimen.

These results indicate that seminal plasma depresses the endogenous respiration of human spermatozoa. The most likely reason for the failure to note this depression until recently (Karjalainen \& Niemi, 1969; Peterson \& Freund, 1970 ) is that no attempt was made to correct for the detrimental effects caused by the washing procedure. The polarographic method is also a more sensitive and quicker technique than the manometric method.

\section{MATERIALS AND METHODS}

Semen samples were obtained from men referred for infertility and from healthy volunteers. The methods used for the collection of semen, its treatment in the laboratory and the determination of oxygen consumption have been described in detail by Eliasson $(1970,1971 \mathrm{a})$. The semen (1 vol.) was diluted with 
the Ringer solution ( 3 vols) and centrifuged at $400 \mathrm{~g}$ for $20 \mathrm{mins}$. The supernatant was aspirated and $3 \mathrm{ml}$ of the buffered Ringer solution added. After gentle mixing, the sample was again centrifuged, the supernatant removed and $1 \mathrm{ml}$ of buffered Ringer solution added.

The sperm density, motility and vitality were determined before and after the washing procedures as well as before and after each determination of oxygen consumption.

The percentage of living cells was estimated by the supravital staining method described by Eliasson \& Treichl (1971).

The buffered Ringer solution had the following composition (mM): $\mathrm{NaCl}$ $123, \mathrm{KCl} 5, \mathrm{MgSO}_{4}$ 1, Tris (Sigma) 37. The $\mathrm{pH}$ was adjusted with $\mathrm{HCl}$ to $8 \cdot 0 \pm 0 \cdot 1$. In addition, the solution contained fructose $(1 \mathrm{mg} / \mathrm{ml})$, human albumin ( $4 \%$; Kabi, Sweden), benzylpenicillin (500 i.u./ml) and streptomycin $(0.2 \mathrm{mg} / \mathrm{ml})$ (modified after Murdoch \& White, 1968).

The oxygen consumption was expressed as $\mathrm{Zo}_{2}$, i.e. $\mu \mathrm{l} \mathrm{O}_{2} / 10^{8}$ cells $/ \mathrm{hr}$.

\section{RESULTS}

Preliminary studies with commonly used salt solutions revealed that the human spermatozoa formed large aggregates during the washing procedure. There was also a marked increase in the percentage of dead cells. Addition of human albumin (final concentration: $4 \%$ ) to the salt solution significantly improved the recovery of vital spermatozoa (see below) but did not abolish their tendency to aggregate.

\section{TABLE 1}

EFFEGT ON THE OXYGEN CONSUMPTION OF HUMAN SPERMATOZOA OF WASHING AND SUSPENSION IN A BUFFERED RINGER SOLUTION

\begin{tabular}{|c|c|c|c|c|}
\hline & \multicolumn{4}{|c|}{$\begin{array}{l}\text { Oxygen consumption of human spermatozoa } \\
\qquad\left(\mu l \mathrm{O}_{2} / 10^{8} \text { cells } / \mathrm{hr}\right)\end{array}$} \\
\hline & \multicolumn{2}{|c|}{ Total number } & \multicolumn{2}{|c|}{ Live cells } \\
\hline & Seminal plasm & Ringer & Seminal plasma & Ringer \\
\hline $\begin{array}{l}\text { Mean } \\
\text { S.D. } \\
\text { Mean of differences, } \mathrm{X}_{\mathrm{D}} \\
\text { S.E. of } \mathrm{X}_{\mathrm{D}} \\
t \text { value }\end{array}$ & $\begin{array}{ll}2 \cdot 7 & \\
1 \cdot 9 & \\
& 3 \\
& 0 \\
& 7\end{array}$ & $\begin{array}{r}5 \cdot 8 \\
2 \cdot 6 \\
9 * * *\end{array}$ & $\begin{array}{ll}4 \cdot 9 & \\
4 \cdot 1 & \\
& 7 \cdot 2 \\
& 1 \cdot 1 \\
& 6 \cdot 5\end{array}$ & $\begin{array}{c}12 \cdot 8 \\
1 \cdot 99 \\
77 * * *\end{array}$ \\
\hline
\end{tabular}

The first experiments were performed with five whole semen specimens from four patients. In these specimens, the oxygen consumption of the spermatozoa was zero. When these cells were suspended in the Ringer solution, the spermatozoa from three of the patients revealed a high $\mathrm{Zo}_{2}(\overline{\mathrm{x}}=66)$ and those from the fourth patient had 'normal' respiratory activity $(\overline{\mathrm{x}}=4 \cdot 7)$.

The next series of experiments was designed to determine if this increase in $\mathrm{ZO}_{2}$ was a general phenomenon. The results are presented in Table 1 . It is evident that the increase in $\mathrm{Zo}_{2}$ when the spermatozoa were transferred to the 
Ringer solution was marked $(P<0.001)$, both when calculated for the total number of spermatozoa and for the live spermatozoa only. (None of the specimens with $\mathrm{Zo}_{2}=0$ is included.)

The effect of the washing procedures on the sperm motility and viability is presented in Table 2. There was a mean decrease in motile cells of $12.5 \%$ and a corresponding increase in the percentage of dead cells. The sum of the motile and dead cells was the same in the two groups and may illustrate the precision of the methods.

In a special experiment, pooled semen was used to obtain sufficient material. The $\mathrm{ZO}_{2}$ (living cells) in the original sample was 5.9. After washing in Ringer solution, it was $9 \cdot 9$. The sample was then recentrifuged and the supernatant

TABLE 2

EFFECTS ON THE MOTILITY AND VIABILITY OF HUMAN SPERMATOZOA OF WASHING AND SUSPENSION IN A BUFFERED RINGER SOLUTION

\begin{tabular}{|c|c|c|c|c|}
\hline & $\begin{array}{l}\text { \% Motile cells } \\
\text { Seminal plasma Ringer }\end{array}$ & $\begin{array}{c}\text { \% Dead cells } \\
\text { Seminal plasma Ringer }\end{array}$ & $\begin{array}{l}\% \text { Motile }+d e \\
\text { Seminal plasma }\end{array}$ & $\begin{array}{l}\text { ad cells } \\
\text { Ringer }\end{array}$ \\
\hline $\begin{array}{l}\text { Mean } \\
\text { S.D. } \\
\text { Mean of differences, } \mathrm{X}_{\mathrm{D}} \\
\text { S.E. of } \mathrm{X}_{\mathrm{D}} \\
t \text { value }\end{array}$ & 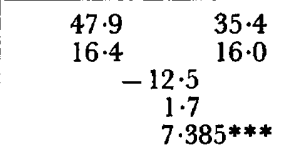 & 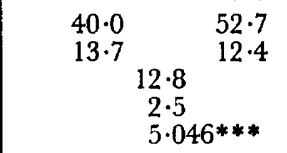 & $\begin{array}{l}87 \cdot 8 \\
12 \cdot 2\end{array}$ & $\begin{array}{l}88 \cdot 1 \\
10.9\end{array}$ \\
\hline
\end{tabular}

exchanged with $1 \mathrm{ml}$ of the original seminal plasma with the result that the $\mathrm{Zo}_{2}$ was lowered to $6 \cdot 8$. The specimen was then once more washed and resuspended in Ringer solution when the $\mathrm{Zo}_{2}$ rose to $9 \cdot 4$. These repeated centrifugations, washings and resuspensions caused a decrease in the percentage of living cells from 60 to 25. Similar results were obtained in three other experiments of this kind. The results clearly demonstrate that the $\mathrm{Zo}_{2}$ calculated per $10^{8}$ living cells is remarkably constant and that the increase of the $\mathrm{Zo}_{2}$ in the Ringer solution cannot be a result of the physical treatment of the spermatozoa.

\section{DISCUSSION}

Due to the low oxygen consumption of human spermatozoa, most experiments concerning the metabolism of these cells have been performed with pooled and washed specimens. It has generally been assumed that the metabolism of the spermatozoa was almost the same in whole semen and in various salt solutions (for references, see Murdoch \& White, 1968; Peterson \& Freund, 1969). In the present study, however, it has been clearly demonstrated that human spermatozoa have a significantly higher oxygen consumption in a buffered Ringer solution at $\mathrm{pH} 8.0$ than in their own seminal plasma. The washing procedure caused about a $13 \%$ decrease in the number of motile cells and a corresponding increase in the percentage of dead cells. The oxygen consump- 
tion was, on the other hand, between 200 and $300 \%$ higher in the buffered Ringer solution than in the whole semen.

Nevo (1966) discussed the possibility that an observed similarity in the oxygen consumption of human spermatozoa in whole semen and in a salt solution could be accidental since no correction was made for the percentage of motile cells present. From the findings of our preliminary studies, the percentage of dead cells would have been high in Nevo's experiments (as well as in those of others) since no colloid was used in the salt solution. The protective effect of albumin was not a pure colloid effect, since the addition of dextran 80 (Pharmacia AB, Sweden) did not influence the recovery of live spermatozoa (unpublished).

Recently, Karjalainen \& Niemi (1969) reported that the respiration of human spermatozoa increased when they were transferred from whole semen to a salt solution. Karjalainen \& Niemi (1969) measured the oxygen consumption by a micro-diver technique, and did not correct for the percentage of motile cells present.

Peterson \& Freund (1970) have also noted that human spermatozoa have a higher oxygen consumption in a salt solution than in seminal plasma. Substrates like malate, pyruvate and glucose did not influence the respiratory activity of the spermatozoa, but a marked increase in oxygen consumption did occur when succinate was added to human spermatozoa both in whole semen and in a salt solution.

In the present study, the corrections for motile and live cells showed a high correlation. The usefulness of these corrections was illustrated by the encouragingly constant $\mathrm{ZO}_{2}$ (per $10^{8}$ living spermatozoa) that was obtained in an experiment during which the proportion of live cells changed from 60 to $25 \%$ due to repeated washings, centrifugations and resuspensions.

The reason for the lower oxygen consumption of spermatozoa in seminal plasma is not clear. It could be due to an inhibitory factor in the seminal plasma or to changes in the ionic milieu. The importance of $\mathrm{pH}$, phosphate concentration and other factors in artificial solutions used for studying the metabolic activity of spermatozoa has been demonstrated by Murdoch \& White (1968) and Peterson \& Freund (1969, 1970). In the present study, a phosphate-free solution was used to avoid an increase in oxygen consumption. The differences in ionic composition between the seminal plasma and the commonly used salt solutions are, however, considerable and the significance of this should be further studied.

Another observation supporting the view that one or more specific factors in the seminal plasma may be responsible for the depressed oxygen consumption is that the sperm respiration in some specimens (mainly from patients with prostate infections) is completely depressed $\left(\mathrm{Zo}_{2}=0\right)$. If the prostatitis is cured, the level of sperm respiration returns to normal (Eliasson, 1970). Interestingly enough, spermatozoa from three out of four patients with $\mathrm{Zo}_{2}=0$ in whole semen had a much higher oxygen consumption in the Ringer solution $(\overline{\mathbf{x}}=66)$ than spermatozoa from samples with normal $\mathrm{Zo}_{2}$.

Human seminal plasma can also depress the oxidative metabolism of rat heart mitochondria (Eliasson, 1971b). However, seminal plasma from semen 
samples with a $\mathrm{Zo}_{2}=0$ did not exhibit a more marked inhibitory effect on the mitochondrial respiration than seminal plasma from normal specimens. A depression of the respiration of the bovine endometrium in vitro by the addition of bull seminal fluid was recently reported by Mather \& Dale (1969). The factor responsible for this inhibition has not yet been identified.

Further studies to investigate the occurrence, nature and physiological significance of the inhibitory factors in human seminal plasma are in progress.

\section{ACKNOWLEDGMENT}

Financial support was given by the Population Council (New York) and the Swedish Research Council (14X-538). The skilful technical assistance of Miss A. Björklung is thankfully acknowledged.

\section{REFERENGES}

Eltasson, R. (1970) Oxygen consumption of human semen. Biol. Reprod. 3, 369.

Eliasson, R. (1971a) Standards for investigation of human semen. Andrologie, 3, 49.

Eliasson, R. (1971b) Inhibitory effect of human seminal plasma on the oxygen consumption of mitochondria. Life Sciences, 10, 407.

Eliasson, R. \& Treichl, L. (1971) Supravital staining of human spermatozoa. Fert. Steril. 22, 134.

Karjalainen, K. \& Niemi, M. (1969) Oxygen consumption of human spermatozoa and seminal plasma as measured by a micro-diver technique. Scand. 7. clin. Lab. Invest. 23, Suppl. 108, 79.

MATHER, E. G. \& DALE, H. E. (1969) Respiratory studies of bovine spermatozoa and endometrial preparations. 7. Reprod. Fert. 20, 401.

Murdoch, R. N. \& White, I. G. (1968) Studies of the metabolism of human spermatozoa. J. Reprod. Fert. 16, 351.

Nevo, A. G. (1966) Relation between motility and respiration in human spermatozoa. F. Reprod. Fert. 11, 19.

Peterson, R. N. \& Freund, M. (1969) Glycolysis by washed suspensions of human spermatozoa. Effect of substrate, substrate concentration, and changes in medium composition on the rate of glycolysis. Biol. Reprod. 1, 238.

Peterson, R. N. \& Freund, M. (1970) ATP synthesis and oxidative metabolism in human spermatozoa. Biol. Reprod. 3, 47. 